\title{
KINETIC NURSING FOR ACUTE SPINAL CORD INJURY PATIENTS
}

\author{
By Barth A. Green, M.D., ${ }^{1}$ Kathy L. Green, R.N., M.S.N. ${ }^{2}$ and \\ K. JoHn KLose, Ph.D. ${ }^{3}$ \\ ${ }^{1}$ Chief, Acute Spinal Injury Unit; Co-Director, South Florida Regional Spinal Cord Injury \\ System; ${ }^{2}$ Instructor, School of Nursing, Miami-Dade Community College; ${ }^{3}$ Director, \\ Central Nervous System Trauma Program, University of Miami School of Medicine
}

Key words: Kinetic Nursing; Roto-Rest Mark I; Acute spinal cord injury; Immobility; Spinal stability.

\section{Introduction}

ACUTE spinal cord injuries are associated with a high degree of morbidity and mortality because of the massive trauma involved as well as the abrupt and severe state of immobility characteristic of these injuries and their treatment. Loss of spinal alignment in cases of spinal instability following injury are often associated with deterioration of neurological function. This loss of function can be secondary to unskilled patient handling or the use of hospital beds or equipment not capable of maintaining alignment during turnings or other treatments (Heiden et al., I975; Smith et al., I975; Keane, I977; Slabaugh \& Nickel, 1978). However, the major cause of high morbidity and mortality reported in most series of acute spinal cord injured patients is cardiopulmonary. The most common pathological states found in these patients are pulmonary oedema, atelectasis, pneumonia and less commonly, pulmonary emboli (Cheshire, I964; Keane, I972; Bellamy et al., I973; Heiden et al., I975). The cardiovascular system is equally devastated by the loss of orthostatic reflexes and the high incidence of thrombo-phlebitis and pulmonary emboli (Deitrick et al., I948; Walsh \& Tribe, I965; Watson, I968; Bidart \& Maury, I973; Hachen, 1974; Silver, 1974; Heiden et al., 1975). A recent series reported an incidence of 100 per cent deep vein thrombosis in acute spinal cord injured patients, using the ${ }^{125} \mathrm{I}$ leg scanning technique (Casas et al., 1976; Todd et al., I976). It has been estimated that over 90 per cent of quadriplegics within 6 months of injury have a documented diagnosis of autonomic dysreflexia resulting in hypertensive episodes with headaches, sweating and spasticity (Olson, 1967; Shea et al., 1973).

A major cause of death in spinal cord injured patients following the acute period, is renal failure (Hackler, 1973). In the acute spinal cord injured patient, the genito-urinary system is often compromised by infections or calcifications with obstructions (Deitrick et al., I948; Whedon et al., I949; Talbot, I968; Hackler, 1973; Lawrence et al., 1973; Burr \& Walsh, 1974; Bergmann et al., I977; Tori \& Hill, I978).

Correspondence: Barth A. Green, M.D., Chief, Acute Spinal Cord Injury, University of Miami School of Medicine, Department of Neurological Surgery (D4-6), P.O. Box or6960, Miami, Florida 33I0I.

This work is supported in part by the National Institutes of Health, NINCDS No. NS I 4468-OI, Rehabilitative Services Administration No. I3-P-59258/4-OI, and by the Paralyzed Veterans of America, Technology and Research Foundation. 
Another system often involved with acute complications following spinal cord injury is the gastro-intestinal tract. Common early complications include paralytic ileus and gastro-intestinal haemorrhage (Langenback, 1969; Heiden et al., 1975). In addition, these patients' metabolic homeostasis is often seriously imbalanced.

The musculoskeletal system is often directly traumatised in these patients. In addition it can be compromised by a significant number of developing problems including: disuse atrophy, contractures (Gassler, I973), spasticity, osteoporosis (Bergmann et al., 1977) with pathological fractures, and heterotopic bone formation (Venier \& Ditunno, 1971; Nicholas, 1973).

The most serious neurological morbidity is the occurrence of deterioration of function after a secondary injury to the spinal cord associated with spinal column instability. Decubitus ulcers present catastrophic problems not only in the acute spinal cord injured patient but also in cases of more chronic paralysing lesions (Carpendale, 1972; Keane, I972; Macauley \& Weiss, 1978).

The Roto-Rest Mark I bed developed by Dr Frank Keane of Ireland has been reported to be of multisystem benefit in the care of paraplegic and quadriplegic patients (Keane, 1967, 1970, I971, 1972, 1977). The Mark I is a versatile intensive care bed which places the patient in perpetual motion with a turning frequency of greater than 200 times per day which may be compared to the usual 12 times per day as performed at conventional nursing units. This bed has been uniquely capable of immobilising acutely injured patients with spinal instability while allowing access to all areas of the body to perform necessary nursing care and other medical treatments. Of special benefit to acute spinal cord injury care are the radio-lucent hatches and mobile surface packs which allow total X-ray surveillance of the patient without compromising spinal alignment.

\section{Methods}

This paper is a summary of a 42-month experience with 105 acute spinal cord injured patients at the South Florida Regional Spinal Cord Injury System at Jackson Memorial Hospital and Miami Veterans Administration Spinal Cord Injury Center. Both centres are affiliated with the University of Miami School of Medicine and staffed by the same neurological and orthopaedic surgery teams. The length of Kinetic Nursing varied from a few hours in patients who died shortly after admission, to several years in the cases of a few high cervical injured quadriplegics. The longest patient treatment interval was three and one-half years following acute injury in the case of a $\mathrm{CI}$ quadriplegic with implanted phrenic nerve stimulators. The majority of the patients were quadriplegic males with an age range between 6 and 82 years with few patients at either extreme. The majority of patients had multiple injuries associated with their spinal cord injury. The ratio of quadriplegics to paraplegics was Io to $\mathrm{I}$. With the limited number of Roto-Rests available, only the more severe injuries were able to be placed in these beds.

\section{Results}

This group of spinal cord injured patients experienced a remarkably low incidence of morbidity and mortality compared to similar reports of conventionally treated patients (Burke et al., 1960; Freed et al., 1966; Guttmann, 1973; Bergman et al., 1977; Mesard et al., 1978). Mortality from cardiopulmonary complications occurred in only seven of the I05 acute spinal cord injured patients. This incidence 
is much lower than reported in other large series (Wolman, 1965; Wilcox, 1972; Heiden et al., 1975). All seven patients were high quadriplegics with severe multiple injuries, five of whom died within I week following admission. The other two died after more than 6 months of Kinetic Nursing and both were high quadriplegics. Injury-related pre-existing respiratory complications responded well to Kinetic Nursing. Only two of the I05 patients developed pneumonitis or atelectasis following the institution of Kinetic therapy. In addition to diminishing stasis of respiratory secretions, the Roto-Rest was shown to be of particular benefit to patients with significant pulmonary shunts (Schimmel et al., 1977). Of special clinical significance was the lack of any identifiable cases of thrombo-phlebitis or pulmonary embolus in the I05 patients. This was attributed to the continuous smooth motion of the Roto-Rest reducing venous stasis (Keane, I972). It has been well documented that cardiovascular stability is difficult to maintain in either a supine or prone position, especially in patients with chest injuries (Olson, 1967). The versatility of postural adjustments of the Mark I allowed effective treatment of patients with neurogenic shock associated with a sympathectomy-like syndrome following acute cervical or upper thoracic injury.

Autonomic dysreflexia has rarely been observed in this group of kinetically nursed acute spinal cord injuries. It has been suggested that this observation might be related to the general decrease of noxious stimuli from complications commonly observed in this group of patients.

There were no observed cases of urinary tract calcifications. The decrease in frequency of upper urinary tract infections observed might be due to diminished urinary stasis or the prevention of reflux contamination with the through-the-table drainage capability of the Roto-Rest bed.

Gastro-intestinal complications were also reduced with only two cases of haemorrhage observed in this group. In addition, a low incidence of paralytic ileus or problems with constipation or fecal impactions were noted. There is no doubt that this apparent decrease in genito-urinary and gastro-intestinal complications must also be credited to the excellent nursing care provided these patients in the spinal cord injury centre setting.

Of special interest was the lack of observed deterioration of function in this series of 105 acute spinal cord injured patients. The ability of the Roto Rest to maintain spinal stability is of great importance to physicians treating these injuries. In addition, these authors observed an excellent fusion rate in both surgically and non-surgically treated spinal fractures nursed in these beds. These observations are attributed to the minimisation of mobility at the fracture site and to the diminished skeletal loss of calcium documented with kinetic care on the Roto Rest (Green, 1976; Keane, I977).

Our staff has made the gross observation that patients nursed on the bed seem to lose less muscle mass and maintain their pre-injury weight to a greater degree than conventionally nursed patients. Dr Keane has performed histological studies to support his similar clinical observations (Keane, 1972).

The incidence of decubitus ulcers was only seven occurrences in 105 patients. Only three of these cases could not be treated appropriately on the Roto-Rest. Two were patients with extreme obesity and one was a patient with extreme emaciation with extraordinary bony prominences. Recent changes in the newer Roto-Rest models have minimised these adjustment difficulties.

Forty-two of the I05 patients received surgery while on the Roto-Rest bed and thus had a continuum of Kinetic Nursing during the pre, and post operative period. We found the Roto-Rest bed to be a most versatile operating room table. 
This capability affords the surgeon the opportunity of maintaining spinal alignment during all phases in the acute care of these patients. Less frequent complaints of fracture site pain have been noted in these patients when compared to other types of conventional beds and frames (Keane, I970; Green, I976; Keane, 1977).

\section{Discussion}

The authors feel that the Roto-Rest Mark I bed and Kinetic Nursing have afforded our patients very definite benefits in the care of their injuries. It has been our experience that air beds, mud beds, sand beds, pellet beds and water beds fail to be of benefit in the treatment of any physiological systems except the skin. Other than the Roto-Rest only the Stoke-Egerton bed allows maintenance of skeletal alignment with turning but even this apparatus lacks the other systemic benefits of Kinetic Nursing (Guttmann, 1973). The Stryker and Circ-o-electric bed have been reported to be ineffective in the management of spinal fractures and acute spinal cord injuries (Coppola, 1977; Slabaugh \& Nickel, 1978). Of special importance in the acute spinal cord injury patient was the significant degree of reduction of cardio-pulmonary complications when compared with conventionally nursed patients with these injuries (Heiden et al., 1975).

Education of the physicians, nurses and allied health staff, as well as the patient and their family and friends are all essential components of a successful Kinetic Nursing programme. Emphasis must be placed on the fact that kinetic therapy is not a substitute for good nursing care but does allow the staff to focus their attention on tasks more skilled than lifting and turning the patient. The RotoRest Mark I bed offers the physicians caring for acute spinal cord injured patients, for the first time, a totally therapeutic tool in their treatment armamentarium (Green, I975; Coppola, I977).

\section{SUMMARY}

This paper is a review of I05 acute spinal cord injured patients treated on the Roto-Rest Mark I hospital bed during a 42-month period at the South Florida Regional Spinal Cord System at the Jackson Memorial Hospital in Miami and the Miami Veterans Administration Hospital Spinal Cord Injury Center. The authors observed that Kinetic Nursing was effective in reducing commonly occurring complications in pulmonary, cardiovascular, skin, musculo-skeletal, nervous, gastro-intestinal, and genito-urinary systems. Of special interest in this patient group was the unique ability to maintain spinal stability while mobilising these acutely injured patients in the Roto-Rest bed.

\section{RÉSUMÉ}

Cette présentation passe en revue I05 lésions médullaires fraîches traitées sur des lits Roto-Rest Mark I pendant une période de 42 mois à l'Hôpital Memorial Jackson à Miami et à l'Hôpital des Vétérans à Miami. Les auteurs soulignent que les soins à donner sur ce lit dit 'kinétique' ont permis de réduire les complications pulmonaires, cardio-vasculaires, cutanés, neurologiques et gastro-intestinal, génito-urinaires. Un très grand intérêt chez les malades traités sur ce lit, est la possibilité de maintenir la stabilité de la colonne vertébrale tout en obtenant une mobilisation de ces blessés (pour ceux qui ne connaissent pas ce lit, il s'agit d'un lit sur lequel le blessé est placé en décubitus dorsal, le lit effectuant de façon constante un retournement alterné avec une fréquence de plus de 200 retournements par 24 heures). 


\section{ZUSAMMENFASSUNG}

Diese Arbeit gibt einen Ueberblick ueber I05 Patienten mit akuten Rueckenmarksverletzungen, die waehrend einer Zeitperiode von 42 Monaten, im 'Roto-Rest Mark I Hospital Bett' in Sued Florida Regional Spinal Cord System im Jackson Memorial Hospital und im Miami Veterans Administration Hospital Spinal Cord Injury Center behandelt wurden. Die Authoren beobachteten, dass die Kinetic Pflege in gewoehnlich auftretenden Komplikationen in Lungen-, Kardiovaskular-, Haut-, Muskel, Skelett-, Nerven-, Magen- und Darm sowie genital und urologischem Systeme effektiv war zu reduzieren. Von besonderem Interesse in dieser Patientengruppe war die einmalige Faehigkeit die Stabilitaet des Rueckgrats zu erhalten, waehrend die akut verletzten Patienten im 'Roto-Rest Bett' mobilisiert wurden.

\section{REFERENCES}

Bellamy, R., Pitts, F. W. \& Stauffer, E. S. (1973). Respiratory complications in traumatic quadriplegia. F. Neurosurg., 39, 596-600.

Bergmann, P., Heilporn, A., Schoutens, A., Paternot, J. \& Tricot, A. (1977). Longitudinal study of calcium and bone metabolism in paraplegic patients. I5, I47-1 50 .

BIDART, Y. \& MAURY, M. (1973). The circulatory behavior in complete chronic paraplegia. Paraplegia, II, I-24.

BuRke, M. H., HiCKs, A. F., Robins, M., et al. (I960, 1972). Survival of patients with injuries of the spinal cord. $\mathcal{F} A M A, \mathrm{I} 2 \mathrm{I}-\mathrm{I} 24$.

BURR, R. G. \& WALSH, J. J. (I974). Urinary calcium and kidney stones in paraplegia. Report of an attempted prospective study. Paraplegia, 12, 2 I-32.

CARPENDALE, M. (1972). A comparison of four beds in the prevention of tissue ischaemia in paraplegic patients. Paraplegia, 12, 2 I-32.

Casas, E. R., Sanchez, M. P., et al. (1976). Prophylaxis of venous thrombosis and pulmonary embolus in patients with acute traumatic spinal cord lesions. Paraplegia, 14, I78-I83.

Chesire, D. J. (1964). Respiratory management in acute traumatic tetraplegia. Paraplegia, I, 252-26I.

Claus-Walker, J., Campos, R. J. \& Carter, R. E. (1972). Calcium excretion in quadriplegia. Arch. Phys. Med. Rehabil., 53, 14-20.

Coppola, A. R. (1977). Stryker-Frame death. Va. Med. Mon., 475-476.

DeITRICK, J. E., WHEDON, G. D. \& SHORR, E. (I948). Effects of immobilization upon various metabolic and physiologic functions of normal men. Am. F. Med., 4, 3-32.

FreED, M. M., BAKST, H. J. \& BARRIE, D. (I966). Life expectancy, survival rates, and causes of death in civilian patients with spinal cord trauma. Arch. Phys. Med. Rehabil., 47, 457-463.

GASSLER, R. (I973). Differential diagnosis of hip contractures in paraplegics and their treatment. Paraplegia, II, 86-87.

Green, B. A. (1976). Kinetic nursing for spinal cord injuries. Paraplegia Life, 5, 4-9.

GReEN, B. A. (1975). Keane Roto-Rest Turning Bed and kinetic nursing. National Paraplegia Foundation Convention Proceedings, 5, I08-I I4.

Guttmann, L. (1973). Spinal Cord Injuries: Comprehensive Management and Research. Oxford, England, Blackwell Scientific Publications.

HACHEN, H. J. (I974). Anticoagulation therapy in patients with spinal cord injury. Paraplegia, 12, I76-I87.

HACKLER, R. H. (I973). Spinal cord injuries-urologic care. Urology, II, I3-18.

Heiden, J. S., Weiss, M. H., Rosenberg, A. W., Apuzzo, M. L. J. \& Kurze, T. (1975). Management of cervical spinal cord trauma in Southern Calif. f. Neurosurg., 43, $732-736$.

JofFE, S. N. (1975). Incidence of post-operative deep vein thrombosis in neurosurgical patients. f. Neurosurg., 42, $20 \mathrm{I}-203$.

Keane, F. X. (1977). Pain and cervical traction variation during manual turning. Paraplegia, 15, 343-348.

KeANE, F. X. (I972). A practical and effective prevention and treatment of decubitus ulceration in paraplegia and other diseases. M.D. Thesis. National Rehabilitation Centre, Dublin, Ireland.

Keane, F. X. (I97I). Mechanical aids to nursing paraplegics. Nurs. Times, 67, I603-1607. $18 / 3-\mathrm{C}$ 
Keane, F. X. (1970). Roto-Rest. Paraplegia, 7, 254-258.

KEANE, F. X. (1967). Roto-Rest. Br. Med. F., 3, 73I-733.

Langenback, R. J. (1969). Gastro-Intestinal Problems in Spinal Cord Injuries, ed. by D. Ruge. Springfield, Illinois, Charles C. Thomas.

LAWrence, G. D., Loeffler, R. G., Martin, L. G. \& Conner, T. B. (I973). Immobilization hypercalcemia: some new aspects of diagnosis and treatment. F. Bone foint Surg. (Am.), 55, 87-94.

Macauley, C. A. \& Weiss, L. (1978). Spinal cord injury in an inner city hospital. Arch. Phys. Med. Rehabil., 59, 76-79.

Mesard, L., Carmody, A., Manarino, E. \& Ruge, D. (1978). Survival after spinal cord trauma. Arch. Neurol., 35, 78-83.

Meyer, G. A., Berman, I. R., Doty, D. B., et al. (I97I). Hemodynamic responses-acute quadriplegia with or without chest trauma. 34, I68-I77.

Nicholas, J. J. (1973). Ectopic bone formation in patients with spinal cord injury. Arch. Phys. Med. Rehabil., 54, 354-359.

Ohry, A., Molmo, M. \& Rozin, R. (1975). Alterations of pulmonary function in spinal cord injured patients. Paraplegia, 13, IOI-IO8.

Olson, E. V. (1967). The hazards of immobility. Am. F. Nurs., 67, 780-797.

RoBerTs, J. B., CURTISs, P. H., Jr. Stability of the thoracic and lumbar spine in traumatic paraplegia following fracture or fracture dislocation. F. Bone foint Surg., 52A, I I I5I 130 .

Schimmel, L., Civetta, J. \& Kirby, R. R. (I977). Treatment of unilateral pulmonary contusion by a new mechanical method to influence pulmonary perfusion. Crit. Care Med., 5, 227-279.

Shea, D. J., Gioffre, R., Carrion, H. \& SMall, M. P. (I973). Autonomic hyper-reflexia in spinal cord injury. South Med. F., 66, 869-872.

SILVER, J. R. (I974). The prophylactic use of anticoagulant therapy in the prevention of pulmonary emboli in one hundred consecutive spinal injury patients. Paraplegia, 12, I88-196.

Slabaugh, P. B. \& Nickel, V. L. (1978). Complications with use of the Stryker Frame. F. Bone foint Surg., 60-2, I I I I-I II2.

SMIth, T. K., Whitaker, J. \& STAuffer, E. S. (1975). Complications associated with the use of the Circular Electric Turning Frame. F. Bone foint Surg., 57, 71 I-7I3.

Talbot, H. (I968). Adjunctive care of spinal cord injury. Surg. Clin. North Am., 48, 737-757.

TodD, J. W., Frisbie, J. H., Rossier, A. B., et al. (1976). Deep venous thrombosis in acute spinal cord injury. A comparison of ${ }^{125}$ I Fibrinogen leg scanning, impedance plethysmography and venography. Paraplegia, 14, 50-57.

Tori, J. A. \& Hill, L. (1978). Hypercalcemia in children with spinal cord injury. Arch. Phys. Med. Rehabil., 59, 443-446.

Venier, L. H. \& DitunNo, Jr., J. F. (I97I). Heterotopic ossification in the paraplegic patient. Arch. Phys. Med. Rehabil., 52, 475-479.

WALSh, J. J., Tribe, C. (I965). Phlebo-thrombosis and pulmonary embolism in paraplegia. Paraplegia, 3, 209-213.

Watson, N. (1968). Venous thrombosis and pulmonary embolus in spinal cord injury. Paraplegia, 6, I I3-I2I.

Whedon, G. D., Deitrick, J. E. \& Shorr, E. (I949). Modification of the effects of immobilization upon metabolic and physiologic functions of normal men by use of an oscillating bed. Am. F. Med., 6, 684-710.

Wilcox, N. E., Stauffer, E. S. (I972). Follow-up of 423 consecutive patients admitted to the Spinal Cord Center, Rancho Los Amigos Hospital, January I to December 31, 1967. Paraplegia, 10, I I5-I22.

Wolman, L. (1965). The disturbance of circulation in traumatic paraplegia in acute and late states: a pathologic study. Paraplegia, 2, 213-226. 